\title{
Severe Maternal Outcomes in a Tertiary Referral Teaching Hospital in Sistan and Baluchistan Province, Iran: A Cross Sectional Study
}

\author{
Zahra Moudi ${ }^{1,}{ }^{,}$, Leyla Arabnezhad ${ }^{1}$ and Seyed Mahdi Tabatabaei ${ }^{2}$ \\ ${ }^{1}$ Pregnancy Health Research Center, Zahedan University of Medical Sciences, Zahedan, Iran \\ ${ }^{2}$ Department of Statistic and Epidemiology, Zahedan University of Medical Science, Zahedan, Iran \\ "Corresponding author: Pregnancy Health Research Center, Zahedan University of Medical Sciences, Zahedan, Iran. Email: zz_moudi@yahoo.com \\ Received 2018 November 12; Accepted 2018 December 10.
}

\begin{abstract}
Background: Since maternal near miss (MNM) could act as a surrogate of maternal death, the implementation of MNM audit at hospital level can provide an opportunity to study maternal morbidity at a large scale.

Objectives: The current study aimed at investigating severe maternal outcomes (SMO; i.e. MNM + maternal death [MD]) in a referral hospital.

Methods: A prospective, facility-based, cross sectional study was conducted from 22 June to 22 December 2017 . The current study was performed in a tertiary referral teaching hospital in Zahedan, Iran. The study population included all pregnant females with a gestational age of 22 weeks giving birth in this hospital or referred to this center for delivery, as well as females within 42 days of pregnancy termination. The World Health Organization maternal near-miss criteria were used to identify MNM and analyze the data. Logistic regression was used to predict SMO risk factors.

Results: Overall, 3527 deliveries and 3480 live births were reported in the hospital under investigation. Severe maternal outcomes were observed in 68 cases. The rate of MNM was 13.79 per 1000 live births; furthermore, the ratio of MNM to mortality was 12:1. Binary analysis showed that hemoglobin level, place of residence, parity, history of cesarean section (CS), insurance coverage, and type of delivery were the significant decisive factors in SMO. Moreover, severe hemorrhage and hypertensive disorders were the common causes of SMO.

Conclusions: According to the collected data, MNM indicators were high in the under study hospital. Therefore, it seems necessary to adopt context-based interventions at hospital level to find and manage mothers prone to SMO during pregnancy and childbirth.
\end{abstract}

Keywords: Near Miss, Healthcare, Quality of Health Care, Maternal Mortality, Morbidity

\section{Background}

Despite the worldwide reduction in maternal mortality (MM) through the increased birth coverage in health facilities (1), the rate of MM remains high in resource-poor settings $(2,3)$. For every female that dies of pregnancyrelated causes, 20 or more cases experience acute or chronic morbidity (4).

The World Health Organization (WHO) defines morbidity as "any health condition attributed to and/or aggravated by pregnancy and childbirth that has a negative impact on the females wellbeing and/or functioning" (5). Maternal morbidity can affect females' physical, psychological, and sexual health, as well as their socioeconomic status. According to the literature, maternal morbidity and mortality is higher among poor females in low- and middle-income countries (6).
For many years, maternal death (MD) reviews are used to improve the quality of care in maternity services (7); however, as MD is the tip of the iceberg, maternal near miss (MNM) was suggested by the WHO (8). The term "near miss" denotes a condition of "a female that nearly died, but survived a complication that occurs during pregnancy, childbirth, or within 42 days of termination of pregnancy" (3). Since MNM could act as a surrogate of maternal death (9), the implementation of MNM audit at hospital level can provide an opportunity to study maternal morbidity at a large scale (4).

The MNM audit involves a set of explicit and measurable criteria for the baseline objective assessment of quality of care, which can be used to monitor care practice and determine if the standards of care are adhered to $(7,8)$. It also provides an objective assessment tool to compare and monitor obstetric quality of care in health facilities among 
females experiencing severe complications over time (7, 10). Moreover, MNM audit is more acceptable for hospital staff to discuss survival causes in such females after experiencing life-threatening conditions $(4,7)$.

There are limited studies investigating MNM in Iran. To the best of authors' knowledge, no studies examined MNM in Sistan and Baluchistan province, Iran. In this province, the rate of MM is 48.6 per 100000 live births (11), while it is 25 per 100000 live births for the whole country (12).

\section{Objectives}

The current study aimed at estimating the potentially life-threatening conditions (PLTC), MNM indicators, and the quality of care using the organ-system dysfunction based approach and MNM tool developed by WHO $(8,13)$ at a provincial referral center in a deprived province of Iran.

\section{Methods}

A prospective, facility-based, cross sectional study was conducted from 22 June to 22 December in 2017 in Zahedan, Iran. Sistan and Baluchistan province has a population size of 2.775 million distributed over a land area of 180726 $\mathrm{km}^{2}$. Zahedan, the capital of the province, entails three hospitals, one of which is Ali-ibn Abi Talib. This center is the only provincial tertiary teaching hospital with a catchment population of about 2221544 people. This hospital also receives referrals from the other two tertiary hospitals in the same city, other district hospitals, health centers, and rural and urban childbirth facilities, as well as self-referring patients. Therefore, Ali-ibn Abi Talib Hospital, as a representative of childbirth facilities, affiliated to Zahedan University of Medical Sciences.

Annually, almost 7000 deliveries are conducted in this hospital. During the study period, the medical staff consisted of 10 obstetricians and 34 midwives. Additionally, midwifery and medical students, as well as obstetrics and gynecology residents provide care for parturient mothers. Mothers and newborns are referred to this hospital in case of the development of any medical/surgical complications or the emergence of unpredicted intrapartum and postpartum complications. Anesthesiologists, obstetricians, and pediatricians are present in the hospital 24 hours a day. This referral hospital is equipped with two intensive care units (ICUs) of 12 beds.

The study population corresponded to all females giving birth at Ali-ibn Abi Talib Hospital or referred to this hospital for childbirth, as well as the ones within 42 days of pregnancy termination. All subjects were females with a gestational age of over 22 weeks. The females diagnosed with abortion or ectopic pregnancy was excluded since the denominator for both abortion and ectopic pregnancy rates was not reliably known.

Females with PLTC were identified based on severe complications (e.g. severe postpartum hemorrhage, severe preeclampsia, eclampsia, sepsis or severe systematic infection, and ruptured uterus) (7).

Furthermore, the organ-system dysfunction based criteria were used to identify MNM cases $(3,8,10)$. According to this approach, an MNM case has one or more specified organ dysfunctions among the following markers: (1) cardiovascular dysfunction (shock, cardiac arrest (absence of pulse/ heart beat and loss of consciousness), continuous consumption of vasoactive drugs, cardiopulmonary resuscitation, severe hypoperfusion (lactate $>5 \mathrm{mM} / \mathrm{L}$ or $>45 \mathrm{mg} / \mathrm{dL}$ ), severe acidosis ( $\mathrm{pH}<7.1)$; (2) respiratory dysfunction (acute cyanosis, gasping, severe tachypnea (respiratory rate $(R R)>40$ breath per minute (BPM), severe bradypnea ( $\mathrm{RR}<6 \mathrm{BPM}$ ), intubation and ventilation not related to anesthesia, severe hypoxemia $\left(\mathrm{O}_{2}\right.$ saturation < $90 \%$ for $\geq 60$ minutes or $\mathrm{PAO}_{2} / \mathrm{FiO}_{2}<200$ ); (3) renal dysfunction (oliguria non-responsive to fluids or diuretics, dialysis for acute renal failure, severe acute azotemia (creatinine $\geq 300 \mu \mathrm{M} / \mathrm{mL}$ or $\geq 3.5 \mathrm{mg} / \mathrm{dL}$ ); (4) coagulation/hematological dysfunction (failure to form clots, massive transfusion of blood or red cells $\geq 5 \mathrm{U}$ ), severe acute thrombocytopenia (< 50000 platelet/mL); (5) hepatic dysfunction (jaundice in the presence of pre-eclampsia, severe acute hyperbilirubinemia (bilirubin $>100 \mu \mathrm{M} / \mathrm{L}$ or $>6.0 \mathrm{mg} / \mathrm{dL}$ ); (6) neurological dysfunction (prolonged unconsciousness (lasting $\geq 12$ hours), coma (including metabolic coma), stroke, uncontrollable fits/status epilepticus, total paralysis); and (7) uterine dysfunction (uterine hemorrhage or infection leading to hysterectomy) $(7,8)$. The current study employed clinical organ dysfunction, laboratory markers of organ dysfunction, and management-based proxies to identify severe organ dysfunction $(7,13)$.

The MNM and death cases (SMO cases) were categorized into two groups, one of which included the females that already met the MNM criteria on admission (i.e. referred from other childbirth facilities, and the number of live births as denominator was unclear), and the other one entailed the ones that gave birth at Ali-ibn Abi Talib Hospital and developed SMO after admission (i.e. near miss cases occurred during childbirth or within 42 days of pregnancy termination). Later, they were categorized as "re- 
ferred from other childbirth facilities" (to show the rate and effectiveness of the emergency referrals) and "gave birth at Ali-ibn Abi Talib Hospital".

Data were collected through daily visits of obstetrics ward and other relevant facilities (e.g. ICU, cardiac care unit, internal medicine, and neurological unit). During the daily visits, the females' medical records were screened for the inclusion criteria, and cases with MNM were followed up until 42 days postpartum. For all females (including near miss cases), the data were extracted from hospital medical records, and then collected into a form adapted from the WHO MNM forms. The WHO maternal near-miss criteria were previously validated $(9,10)$.

All data were transferred into SPSS version 16, and a copy of MNM records was prepared for the subsequent follow-ups, as well as for the substantiation of data accuracy. After entering the data into the software, they were checked for the accuracy by the research team. Moreover, all the cases with MNM were entered into an online system called "IMAN". Then, these cases were checked by an expert at Iranian Ministry of Health and Medical Education, and the accuracy was verified. Additionally, information related to the patients' demographic characteristics, hospital admission, duration of hospital stay, as well as maternal and perinatal outcomes (to monitor the performance and quality of obstetric services in the hospital itself) (8) was recorded for all participants.

The current study protocol was approved by the Ethics Committee of Zahedan University of Medical Sciences (ZAUMS), Zahedan, Iran (July 9, 2017; IR.AUMS.REC:1396. 82). In addition, permission was obtained from the managers of Ali-ibn Abi Talib Hospital.

The data were analyzed with SPSS version 16 . The results were presented as frequencies and percentages (for categorical variables), as well as mean and standard deviations (for continuous variables). Chi-square test was used to compare demographic qualitative variables among the three groups [(1) The females that already met the MNM criteria on admission (i.e. referred from other childbirth facilities), (2) Mothers that gave birth at Ali-ibn Abi Talib Hospital and developed SMO after admission (i.e. near miss manifestations occurred during childbirth or within 42 days of pregnancy termination, (3) Females without MNM], and two-tailed tests were run to compare the variables. P-values $<0.05$ were considered statistically significant.

The results were presented in accordance with WHO criteria regarding MNM 8. The MNM ratio (MNMR) refers to the number of MNM cases per 1000 live births (MNMR = MNM/LB). The SMO ratio was also obtained by inspecting the number of females with life-threatening conditions (i.e. MNM + MD) per 1000 live births. Moreover, mortality index (MI\%) was calculated as MD/(MNM + MD) $\times 100$. Hospital access indicators were also estimated by the calculation of SMO12 [cases presenting the organ dysfunction or maternal death within 12 hours of hospital stay (SMO12) (number), proportion of SMO12 cases among all SMO cases, proportion of SMO12 cases coming from other health facilities, and SMO12 mortality index: The number of SMO12 cases divided by the number of all SMO cases was expressed as a percentage].

Logistic regression model was used to estimate the association between SMO ( $0=$ without SMO, $1=$ SMO $)$ and independent variables (type of delivery, age, parity, maternal education, place of residence, insurance coverage, history of CS, and anemia). All independent variables were considered categorical (dichotomous).

The forward stepwise method was adopted in logistic regression to study the role of each independent variable on SMO event among females with previous CS. Pvalue of 0.05 was selected to allow a variable to enter the model or retain a variable (as an independent variable) in the model. The overall goodness-of-fit was tested by the Hosmer-Lemeshow test and likelihood statistics. The twotailed tests were also employed to compare the variables between groups. P-values $<0.05$ were considered statistically significant.

\section{Results}

A total of 3527 deliveries (including 3 triplets and 65 twins) were reported during the six-month period of data collection in the Ali-ibn Abi Talib Hospital. The SMOs were developed in 68 cases ( 60 near-miss cases and eight maternal deaths). In this regard, four cases of MM (50\%) and 12 cases of near miss (20\%) were referred from other health facilities. In this phase, since the denominator (i.e. the number of live births) was not specified for the referrals, these cases were not included in the calculation of SMO and MNM indicators (Table 1); however, they are shown in the other tables in a separate column.

Overall, 3480 deliveries were live births. A total of 52 cases of SMO (i.e. 48 MNMs and four MDs) occurred in Aliibn Abi Talib Hospital. The MNM and SMO ratios were 13.79 and 14.94 cases per 1000 live births, respectively. Furthermore, MNM to mortality ratio was 12:1 (Table 1).

Table 2 tabulates the demographic characteristics of all females (with and without an SMO) admitted to Ali-ibn Abi Talib Hospital. The SMO showed a significant association 


\begin{tabular}{lc}
\hline Table 1. MNM Indicators in the Studied Mothers & \\
\hline & No. $(\%)$ \\
\hline Total number of live births in Ali-ibn Abi Talib Hospital & 3480 \\
SMO cases & 52 \\
\hline MNM cases & 48 \\
\hline Maternal death $\quad$ Near-Miss Indicators & 4 \\
\hline SMO ratio(SMOR/100o live births) & 14.94 \\
\hline MNM incidence ratio (MNM/LB $\times$ 1000 live births) & 13.79 \\
\hline MNM: mortality ratio $($ MNM: 1 maternal death) & $12: 1$ \\
\hline Mortality index [MD/(MNM + MD) $\times$ 100] & $8.33 \%$ \\
\hline
\end{tabular}

with nationality $(\mathrm{P}<0.001)$, place of residence $(\mathrm{P}<0.001)$, and insurance coverage $(\mathrm{P}<0.001)$.

The MNM cases were identified according to organ dysfunctions (Table 3). In this regard, coagulation/hematological disorders (71.15\%) were the most common organ dysfunctions among females with SMO (i.e. MNM and MD) that gave birth in Ali-ibn Abi Talib Hospital. The other organ dysfunctions included uterine dysfunction leading to hysterectomy (32.69\%), and respiratory dysfunction $(17.30 \%)$. In contrast, coagulation/hematological (87.5\%), neurological (56.25\%), and respiratory (43.75\%) dysfunctions were reported as the three most common organ dysfunctions among females with SMO referred from other childbirth facilities (Table 3).

Laparotomy was performed in eight females with SMO. The causes of laparotomy were severe infection $(n=2$; leading to laparotomy and hysterectomy), severe postpartum hemorrhage $(n=4)$, post-cesarean section splenic rupture $(\mathrm{n}=1)$, and massive hematoma in the broad ligament and ovaries $(\mathrm{n}=1)$.

Regarding the females giving birth at Ali-ibn Abi Talib Hospital, anemia was twice more common among the ones with SMO (46.15\%) than those without it (21.21\%). Moreover, previous cesarean section was 1.8 times more prevalent among females with SMO (57.69\%) than the ones without it (32.55\%). Furthermore, uterine rupture was five times more common among females with SMO $(n=5)$ than the ones without it $(\mathrm{n}=1)$.

Out of the 68 cases with SMO (i.e. MNM and MD), 57 cases $(83.82 \%)$ were diagnosed with organ dysfunction or led to MD within the first 12 hours of hospital admission, $28.07 \%$ of whom $(n=16)$ were referred from other childbirth facilities (Table 4).

Eight cases of MD were reported among SMO cases, four cases of which were due to indirect causes (i.e. deterioration of a pre-existing medical problem aggravated by pregnancy), including renal failure with serum creatinine level of $12 \mathrm{mg}(\mathrm{n}=1)$, thrombotic thrombocytopenic purpura with platelet count of $3000(n=1)$, acute respiratory distress syndrome in a females with drug abuse $(\mathrm{n}=1)$, and encephalopathy (with an unknown etiology; $n=1$ ). The other four MD cases were caused by problems directly related to pregnancy, including placental abruption and disseminated intravascular coagulation $(\mathrm{n}=2)$, as well as hypertensive disorders (severe preeclampsia; $n=2$ ). Among all the pregnant females giving birth at the Ali-ibn Abi Talib Hospital, the overall ICU admission rate was 1.33\%; meanwhile, this rate was obtained as $58.82 \%$ among the females with SMO (Table 5).

The overall model goodness-of-fit tests for the HosmerLemeshow test $\left(\chi^{2}=4.36, \mathrm{df}=7, \mathrm{P}=0.73\right)$, and likelihood statistics $\left(-2\right.$ log-likelihood $=596.819$, Cox and Snell $R^{2}=$ 0.02 , Negekerke $R^{2}=0.12$ ) were performed well. According to the logistic regression model, age, and maternal education were not included in the model (Table 6), although these variables may affect experiencing SMO. The results also revealed that $\mathrm{Hb}$ level, place of residence, parity, history of CS, insurance coverage, and type of delivery were significant predictors of SMO. According to the data, while females with giving birth for the second time, having history of CS, and undergoing CS were more prone to SMO, insurance coverage, living in the urban areas, and $\mathrm{Hb} \geq 11$ $\mathrm{g} / \mathrm{dL}$ had protecting effects against SMO.

\section{Discussion}

The current study was the first attempt to document SMO cases (i.e. MNM + MD) based on the WHO criteria and investigate the presence of organ dysfunction or failure (8) at a referral hospital in a deprived province with the highest MM rate in Iran. Based on the evidence, MNM ratio and other indicators of severe MM were much higher in this referral hospital than the ones in the economically advantaged provinces of Iran and the overall ranges reported by WHO (8).

In the current study, MNM ratio (13.79 per 1000 live births) was higher than the overall ratio reported by the WHO (8.3 per 1000 live births). According to a multicountry study performed by the WHO, the overall MNM ratio in the current study can be placed into the category of countries with "very high MM ratio" (14). Additionally, at the national level, the current study results (MNM ratio of 13.79 per 1000 live births) were much higher than those 


\begin{tabular}{|c|c|c|c|c|}
\hline & \multirow{2}{*}{ Without SMO, $\mathbf{N}=3475(98.08 \%)$} & \multicolumn{2}{|c|}{ With SMO, N = $68(1.92 \%)$} & \multirow{2}{*}{ P Value } \\
\hline & & $\begin{array}{l}\text { Gave Birth at the Studied } \\
\text { Hospital, N = 52 (1.47\%) }\end{array}$ & $\begin{array}{l}\text { Referred from Other Childbirth } \\
\text { Facilities, } N=16(0.54 \%)\end{array}$ & \\
\hline \multicolumn{5}{|l|}{ Nationality } \\
\hline Iranian & $2957(85.09)$ & $35(67.31)$ & $13(81.25)$ & \\
\hline Foreigner $^{\mathrm{b}}$ & $518(14.91)$ & $17(32.69)$ & $3(18.75)$ & 0.001 \\
\hline \multicolumn{5}{|l|}{ Age, $y$} \\
\hline $13-19$ & $433(12.46)$ & $4(7.69)$ & $1(6.25)$ & \\
\hline $20-30$ & $1795(51.65)$ & $21(40.39)$ & $8(50)$ & \\
\hline$\geq 31$ & $1247(35.89)$ & $27(51.92)$ & $7(43.75)$ & 0.1 \\
\hline \multicolumn{5}{|l|}{ Education } \\
\hline Illiterate & $959(27.60)$ & $20(38.46)$ & $7(43.75)$ & \\
\hline Primary school & $1401(40.32)$ & $24(46.16)$ & $5(31.25)$ & \\
\hline $\begin{array}{l}\text { Secondary school } \\
\text { and higher }\end{array}$ & $1115(32.08)$ & $8(15.38)$ & $4(25)$ & 0.05 \\
\hline \multicolumn{5}{|l|}{ Residence } \\
\hline Urban & $2965(85.32)$ & $40(76.92)$ & $9(56.25)$ & \\
\hline Rural & $510(14.68)$ & $12(23.08)$ & $7(43.75)$ & 0.007 \\
\hline \multicolumn{5}{|l|}{ Insurance } \\
\hline Yes & $2889(83.14)$ & $35(67.31)$ & $12(75)$ & \\
\hline No & $586(16.86)$ & $17(32.69)$ & $4(25)$ & 0.009 \\
\hline \multicolumn{5}{|l|}{ Parity } \\
\hline 1 & $776(22.33)$ & $7(13.46)$ & $2(12.5)$ & \\
\hline $2-5$ & $1661(47.80)$ & $35(67.31)$ & $10(62.5)$ & \\
\hline$>5$ & $1038(29.87)$ & $10(19.23)$ & $4(25)$ & 0.05 \\
\hline
\end{tabular}

Abbreviation: SMO, Severe maternal outcomes.

${ }^{a}$ Values are expressed as No. (\%).

${ }^{\mathrm{b}}$ Two Pakistanis and the others from Afghanistan.

of the Alborz province (4.97 per 1000 live births), an economically advantaged province near Tehran, the capital of Iran (15).Since both of these studies used the same (i.e. organ dysfunction) criteria to determine MNM cases, the results can reflect the true disparities of maternal health outcomes in the country.

Individuals' health status is determined by the interaction of several factors including physical and socioeconomic environment (e.g. urban and rural location, education, poverty level), individual characteristics and behavior, and medical care system (e.g. preventive and tertiary care) (16). According to the literature, Sistan and Baluchis$\tan$ province is ranked as the least developed province of Iran in terms of the development indices (e.g. revenue, education, welfare, and health-related mediator factors) (17, 18).
Disparities among and within countries in terms of health determinants are accompanied by poor health indices (17). For instance, iron deficiency anemia is highly prevalent among pregnant females in Sistan and Baluchestan province (44.2\%) in comparison with other provinces of Iran (19). It is also observed that the personal and medical characteristics of females (e.g. age $>31$ and anemia) can affect postnatal severe complications $(20,21)$ and SMO incidence $(22,23)$.

On the other hand, passing through the obstetric transition trends towards over-medicalization (e.g. unnecessary C-section) in the middle- and low/middle-income countries exposes females to increased risk (24). According to the literature, females with previous C-section are more prone to SMO due to the increased risk of uterine rupture after vaginal birth and severe bleeding (25). In line 


\begin{tabular}{|c|c|c|c|}
\hline \multirow{2}{*}{ Morbidity Conditions } & \multirow[b]{2}{*}{ Without SMO, N = $3475(98.08 \%)$} & \multicolumn{2}{|c|}{ With SMO, N = $68(1.92 \%)$} \\
\hline & & $\begin{array}{l}\text { Gave Birth at the Studied Hospital; } \\
\qquad N=52(1.47 \%)\end{array}$ & $\begin{array}{l}\text { Referred from Other Childbirth } \\
\text { Facilities; } N=16(0.54 \%)\end{array}$ \\
\hline \multicolumn{4}{|c|}{ 1.1. Females with Severe Complications/Potentially Life-threatening Conditions } \\
\hline Severe hemorrhage & $55(1.58)$ & $29(55.77)$ & $4(25)$ \\
\hline Severe preeclampsia/eclampsia & $195(5.61)$ & $16(30.77)$ & $6(37.5)$ \\
\hline $\begin{array}{l}\text { Sepsis or severe systemic } \\
\text { infection }\end{array}$ & $18(0.52)$ & $1(1.92)$ & $3(18.75)$ \\
\hline Rupture of uterus & $1(0.03)$ & $5(9.61)$ & $1(6.25)$ \\
\hline Other medical conditions & $14(0.40)$ & $6(11.54)$ & $3(18.75)$ \\
\hline \multicolumn{4}{|c|}{ Contributory Causes/Associated Conditions } \\
\hline Anemia, $\mathrm{Hb}<11^{\mathrm{b}}$ & $737(21.21)$ & $24(46.15)$ & - \\
\hline History of CS & $1131(32.55)$ & $30(57.69)$ & $6(37.5)$ \\
\hline \multicolumn{4}{|l|}{ 1.2. Undergoing Critical Interventions } \\
\hline Hysterectomy & $0(0)$ & $17(32.69)$ & $2(12.5)$ \\
\hline Laparotomy & $0(0)$ & $4(7.69)$ & $4(25)$ \\
\hline Receiving blood products & $67(1.93)$ & $36(69.23)$ & $12(75)$ \\
\hline \multicolumn{4}{|c|}{ Organ Dysfunction/Life-threatening Conditions (Near-miss Criteria) } \\
\hline Cardiovascular & - & $4(7.69)$ & $5(31.25)$ \\
\hline Respiratory & - & $9(17.30)$ & $7(43.75)$ \\
\hline Renal & - & $7(13.46)$ & $6(37.5)$ \\
\hline Coagulation/hematological & - & $37(71.15)$ & $14(87.5)$ \\
\hline Hepatic & - & $2(3.84)$ & $6(37.5)$ \\
\hline Neurological & - & $6(11.54)$ & $9(56.25)$ \\
\hline Uterine/hysterectomy ${ }^{\mathrm{b}}$ & - & $17(32.69)$ & $2(12.5)$ \\
\hline
\end{tabular}

Abbreviation: SMO, Severe maternal outcomes.

a Values are expressed as No. (\%).

${ }^{\mathrm{b}}$ Level of hemoglobin $(\mathrm{Hb})$ during pregnancy; prenatal $\mathrm{Hb}$ level was not available for referral cases.

with previous studies, disease susceptibility and proneness to severe pregnancy complications may partly explain the high prevalence of MNM in this hospital $(26,27)$.

Based on the current study data, about $32 \%, 23 \%$, and $7.7 \%$ of the females that gave birth at this hospital and developed SMO had no insurance coverage, lived in rural areas, and were adolescents, respectively. Even in countries in which most of females have access to resource services, some females have no access to high-quality childbirth care services and experience worse outcomes due to geographical location, age, and lack of financial protection (28).

In the current study, MM index was 7.69\%. According to the WHO, the adoption of proper healthcare services in dealing with complex and severe cases would reduce the MM index to below $5 \%$ (8). Consistent with other studies, the high MM index in the current study can be explained by suboptimal obstetric care and/or severity of the cases (29).

In the current study, the rate of SMO12 among all the cases with SMO was $83.82 \%$ of which $28.07 \%$ were referred from other health facilities, showing that referral cases were higher in the current study than that of a previous study performed in Alborz province (3\%) (15). The referral hospital under study receives and manages complicated cases, sometimes in deteriorated critical conditions, referred from other healthcare centers. This indicates poorquality obstetric services at the initial site and delayed referral of the cases $(30,31)$.

According to the literature, the receipt of care from a not very well-equipped childbirth facility with inexperienced staff is associated with delayed and inappropriate care (32). In the current study, $25 \%(n=4)$ of the females referred from other childbirth facilities eventually died. This indicates that females referred late to the hospital did not benefit from specialized treatments in the tertiary hospital under study.

Furthermore, it is noteworthy that about $61 \%$ of females that gave birth at this hospital and developed SMO were self-referrals, and about $8 \%$ of them did not receive any treatments at the initial hospital. In the developing countries, health system serves through a network; however, this may not always function properly (33). In the ab- 


\begin{tabular}{|c|c|c|c|}
\hline & \multirow{2}{*}{ Without SMO, N = 3475 (98.08\%) } & \multicolumn{2}{|c|}{ With SMO, N = $68(1.92 \%)$} \\
\hline & & $\begin{array}{l}\text { Gave Birth at the Studied Hospital; } \\
\qquad \mathrm{N}=52(1.47 \%)\end{array}$ & $\begin{array}{c}\text { Referred from Other Childbirth } \\
\text { Facilities; } \mathrm{N}=16(0.54 \%)\end{array}$ \\
\hline \multicolumn{4}{|l|}{ Source of Referral } \\
\hline Self-referral & $3129(90.04)$ & $32(61.54)$ & $4(25)$ \\
\hline $\begin{array}{l}\text { Self-referral after } \\
\text { non-admission to other } \\
\text { hospitals of the city }\end{array}$ & $18(0.52)$ & $4(7.69)$ & 0 \\
\hline Health centers & $105(3.02)$ & $5(9.62)$ & $1(6.25)$ \\
\hline Rural delivery centers & $210(6.04)$ & $8(15.38)$ & $2(12.5)$ \\
\hline Other cities & $13(0.35)$ & $3(5.77)$ & $9(56.25)$ \\
\hline \multicolumn{4}{|l|}{ Reasons for Admission to the Hospital } \\
\hline Labor pain & $2390(68.78)$ & $12(23.08)$ & 0 \\
\hline Prenatal complications & $599(17.24)$ & $32(61.54)$ & 0 \\
\hline Intrapartum complications & $63(1.81)$ & $2(3.85)$ & 0 \\
\hline Postpartum complications & $19(0.55)$ & 0 & $14(87.5)$ \\
\hline Elective cesarean section & $396(11.39)$ & $6(11.53)$ & 0 \\
\hline $\begin{array}{l}\text { Non-obstetric medical and } \\
\text { surgical illnesses }\end{array}$ & $8(0.23)$ & 0 & $2(12.5)$ \\
\hline \multicolumn{4}{|l|}{ Hospital Access Indicators } \\
\hline \multicolumn{4}{|l|}{ Time of diagnosis } \\
\hline Before admission to hospital & & $7(13.46)$ & $10(62.5)$ \\
\hline Less than $12 \mathrm{~h}$ of admission & & $34(65.39)$ & $6(37.5)$ \\
\hline After $12 \mathrm{~h}$ of admission & & $11(21.15)$ & 0 \\
\hline
\end{tabular}

sence of clear guidelines, hospitals may refuse to treat females with complications (34). Based on the evidence, this can be related to negligence, lack of skill, or the supplies necessary to initiate the treatment (32).

In addition, in the current study, the ICU admission rate was $1.33 \%$ among all females, which was higher than the rate $(0.7 \%)$ reported in Alborz province, Iran (15). According to the WHO, the minimum acceptable overall rate of ICU admission is $0.5 \%$. Nonetheless, if the audit was performed in tertiary health facilities with more cases of complexity, higher rates of ICU admission rate could be reported (8).

The ICU admission rate was $85.11 \%$ among females with SMO, which was within the suggested limit of over $70 \%$ by WHO. This indicated that a substantial proportion of females were admitted just for monitoring purposes (8). Moreover, the rate of MD occurrence without ICU admission was $12.5 \%$. The WHO announced that the incidence of over $10 \% \mathrm{MM}$ without ICU admission is indicative of the lack of ICU beds (8). In the current study, a female with total placental abruption and coagulation disorders died during the surgery three hours post-admission to the hospital. She arrived at the hospital too late to be admitted to the ICU. In the current study, high SMO and MNM ratio suggested that much more care and resources are needed to improve the outcomes in such health facilities $(8,22)$. Therefore, with regard to the specific condition of the province under study, strategies and plans should be designed based on the context-specific causes.

Meanwhile, literature review showed that although SMO (i.e. MNM and MD) acts as a positive entry point and provides valuable information; it is not enough to create sustainable changes in obstetric care. Therefore, it is recommended that direct interviews be conducted with survivors and service providers to obtain a deeper understanding regarding the deficiencies in care provision, thereby improving the quality of obstetric care $(4,7,35)$.

The current study had some limitations that should be addressed. First, it was conducted only in one tertiary (referral teaching) hospital in the capital city of Sistan and Baluchistan province. Therefore, it does not represent cases of SMO (i.e. MNM and MD) occurring in other childbirth facilities. However, a hospital-based data collection allows policy makers to use pooled data to identify trends 
Table 5. Pregnancy Outcomes and Intensive Care Use Among All Females ${ }^{\mathrm{a}, \mathrm{b}}$

\begin{tabular}{|c|c|c|c|}
\hline & \multirow{2}{*}{ Without SMO, N = 3475 (98.08\%) } & \multicolumn{2}{|c|}{ With SMO, N = $68(1.92 \%)$} \\
\hline & & $\begin{array}{l}\text { Gave Birth at the Studied Hospital, } \\
\qquad N=52(1.47 \%)\end{array}$ & $\begin{array}{l}\text { Referred from Other Childbirth } \\
\text { Facilities, } N=16(0.54 \%)\end{array}$ \\
\hline Preterm birth delivery, wk & $1176(33.84)$ & $37(71.15)$ & c \\
\hline Less than $28^{d}$ & $52(1.50)$ & $6(11.54)$ & \\
\hline $28-32$ & $88(2.53)$ & $7(13.46)$ & \\
\hline $32-37$ & $1036(29.81)$ & $24(46.15)$ & \\
\hline Stillbirth & $106(3.05)$ & $13(25)$ & $5(31.25)$ \\
\hline Cesarean section & $1696(48.81)$ & $43(82.69)$ & $6(37.5)$ \\
\hline Maternal mortality & 0 & 4 & 4 \\
\hline \multicolumn{4}{|c|}{ Intensive Care Use } \\
\hline ICU admission rate & $7(0.2 \%)^{e}$ & $29(55.8 \%)$ & $11(68.8 \%)$ \\
\hline \multicolumn{4}{|l|}{ ICU use } \\
\hline Mean \pm SD & $2.14 \pm 1.46$ & $3.24 \pm 1.64$ & $13.45 \pm 11.99$ \\
\hline Min - Max, d & $1-5$ & $1-8$ & $1-30$ \\
\hline \multicolumn{4}{|c|}{$\begin{array}{l}\text { Abbreviations: SMO, Severe maternal outcomes; ICU, Intensive care unit. } \\
\text { a Values are expressed as No. (\%). } \\
\text { b Total number of females giving birth: } \mathrm{n}=3480 \text {. ICU admission rate among females with SMO: } 58.82 \% \text {. SMO rate among females admitted to ICU: } 0.85 \% \text {. Percentages of } \\
\text { maternal death occurred without ICU admission: } 12.5 \% \text {. } \\
{ }^{c} \text { No data about gestational age was provided in referral records. } \\
{ }^{d} \text { WHO (10 Feb 2018). Preterm birth.www.who.int/en/news-room/fact-sheets/detail/preterm-birth. } \\
\text { e Of these seven females, one and six were transferred to the ICU to receive intensive care due to postpartum hemorrhage and preeclampsia, respectively. }\end{array}$} \\
\hline
\end{tabular}

Table 6. The Final Multivariable Logistic Regression Model of Variables Associated with SMO Event

\begin{tabular}{|c|c|c|c|c|c|c|}
\hline Variable & $\beta$ Coefficient & SE & Wald & PValue & Exp. $(\beta)$ & 95\% CI (Lower - Upper) \\
\hline \multicolumn{7}{|l|}{ Hb level, g/dL } \\
\hline \multicolumn{7}{|l|}{$<11$} \\
\hline$\geq 11$ & -1.47 & 0.25 & 34.70 & $<0.001$ & 0.22 & $0.14-0.37$ \\
\hline \multicolumn{7}{|l|}{ Place of residence } \\
\hline \multicolumn{7}{|l|}{ Rural areas } \\
\hline Urban areas & -0.74 & 0.28 & 6.92 & 0.009 & 0.47 & $0.27-0.82$ \\
\hline \multicolumn{7}{|l|}{ Insurance coverage } \\
\hline \multicolumn{7}{|l|}{ No } \\
\hline Yes & -1.08 & 0.27 & 15.04 & $<0.001$ & 0.33 & $0.19-0.58$ \\
\hline \multicolumn{7}{|l|}{ Parity } \\
\hline \multicolumn{7}{|l|}{1} \\
\hline$\geq 1$ & 0.75 & 0.36 & 4.23 & 0.04 & 2.12 & $1.03-4.36$ \\
\hline \multicolumn{7}{|l|}{ History of CS } \\
\hline \multicolumn{7}{|l|}{0} \\
\hline$\geq 1$ & 0.67 & 0.31 & 4.79 & 0.02 & 1.97 & $1.07-3.61$ \\
\hline \multicolumn{7}{|l|}{ Type of delivery } \\
\hline \multicolumn{7}{|l|}{ Vaginal } \\
\hline CS & 0.76 & 0.33 & 5.07 & 0.02 & 2.14 & $1.10-4.16$ \\
\hline
\end{tabular}


based on the patients' characteristics, hospital-based facilities for critical care (e.g. ICU), geographical considerations, and inter-hospital comparisons (13).

Second, the current study was hospital-based, and there was no information regarding the SMO cases that occurred following home births. In addition, abortion and ectopic pregnancies were not included in the study. Therefore, the current study findings cannot be extrapolated to other settings. As a result, a multicenter study should be conducted to obtain a broader understanding of deficiencies in the provision of obstetric care in this province that has a high maternal mortality rate in Iran.

\subsection{Conclusion}

The results of the current study indicated a high incidence rate for SMO in the large tertiary referral teaching hospital investigated in the study. The current study could be the first step toward the gradual implementation of the MNM approach across the province. Moreover, it can help policymakers and local authorities to conduct some of the required context-based interventions in the light of the current study findings. It is noteworthy that direct interviews with survivors and service providers are necessary to provide a deeper understanding of the root causes of SMO. Therefore, performing the necessary interventions in each health facility seems to be mandatory.

\section{Acknowledgments}

Authors would like to thank the managers and staff of Ali-ibn Abi Talib Hospital and the authorities of Zahedan University of Medical Sciences, Zahedan, Iran, for their financial support (grant No. 8315, July 23, 2017).

\section{Footnotes}

Authors' Contribution: Leyla Arabnezhad: organizing the field activities and retrieving data in the field; Zahra Moudi: writing of the manuscript. All authors participated in the study design, providing concepts, and revising the manuscript. They also contributed to interpreting the evidence and critically revising the manuscript.

Conflict of Interests: Authors declared no conflict of interests.

Ethical Considerations: The study was approved by the Ethics Committee of Zahedan University of Medical Sciences (ZAUMS), Zahedan, Iran (July 9, 2017; IR.AUMS.REC: 1396. 82). In addition, permission was obtained from the directors of Ali-ibn Abi Talib Hospital.
Funding/Support: Zahedan University of Medical Sciences, Zahedan, Iran.

\section{References}

1. World Health Organization. Standards for improving quality of maternal and newborn care in health facilities. Geneva: WHO Document Production Services; 2016.

2. World Health Organization. Quality, equity, dignity: The network to improve quality of care for maternal, newborn and child health - strategic objectives. Geneva: WHO Document Production Services; 2017.

3. Say L, Souza JP, Pattinson RC; WHO Working Group on Maternal Mortality and Morbidity Classifications. Maternal near misstowards a standard tool for monitoring quality of maternal health care. Best Pract Res Clin Obstet Gynaecol. 2009;23(3):287-96. doi: 10.1016/j.bpobgyn.2009.01.007. [PubMed: 19303368].

4. Kalhan M, Singh S, Punia A, Prakash J. Maternal near-miss audit: Lessons to be learnt. Int J Appl Basic Med Res. 2017;7(2):85-7. doi: 10.4103/2229-516X.205815. [PubMed: 28584736]. [PubMed Central: PMC5441269].

5. Machiyama K, Hirose A, Cresswell JA, Barreix M, Chou D, Kostanjsek $\mathrm{N}$, et al. Consequences of maternal morbidity on health-related functioning: A systematic scoping review. BMJ open. 2017;7(6). e013903. doi: 10.1136/bmjopen-2016-013903.

6. Firoz T, Chou D, von Dadelszen P, Agrawal P, Vanderkruik R, Tuncalp $\mathrm{O}$, et al. Measuring maternal health: Focus on maternal morbidity. Bull World Health Organ. 2013;91(10):794-6. doi: 10.2471/BLT.13.117564. [PubMed: 24115804]. [PubMed Central: PMC3791656].

7. Tuncalp O, Souza JP. Maternal near-miss audits to improve quality of care. BJOG. 2014;121 Suppl 4:102-4. doi: 10.1111/1471-0528.12868. [PubMed: 25236642].

8. World Health Organization. Evaluating the quality of care for severe pregnancy complications: The WHO near-miss approach for maternal health. Geneva: WHO Document Production Services; 2011.

9. Nelissen E, Mduma E, Broerse J, Ersdal H, Evjen-Olsen B, van Roosmalen J, et al. Applicability of the WHO maternal near miss criteria in a low-resource setting. PLoS One. 2013;8(4). e61248. doi: 10.1371/journal.pone.0061248. [PubMed: 23613821]. [PubMed Central: PMC3629023].

10. Souza JP, Cecatti JG, Haddad SM, Parpinelli MA, Costa ML, Katz $\mathrm{L}$, et al. The WHO maternal near-miss approach and the maternal severity index model (MSI): Tools for assessing the management of severe maternal morbidity. PloS one. 2012;7(8). e44129. doi: 10.1371/journal.pone.0044129. [PubMed: 22952897]. [PubMed Central: PMC3430678].

11. Kamiabi F, Torkestani F, Abedini M, Haji Maghsoudi S, Rastegari A, Hejazi S, et al. [Analysis of the maternal mortality in Iran, 2007-2012]. J Kerman Univ Med Sci. 2015;22(6):650-68. Persian.

12. World Health Organization. World health statistics 2017, monitoring health for the SDGs, Sustainable Development Goals. Geneva: World Health Organization; 2017.

13. Campbell ME, Barrett J. Maternal morbidity and near misses: Determining the real numbers. In: Arulkumaran S, Karoshi M, Keith LG, Lalonde AB, B-Lynch C, editors. A comprehensive textbook of postpartum hemorrhage. An essential clinical reference for effective management. 2nd ed. 2012. p. 147-51.

14. Souza JP, Gulmezoglu AM, Vogel J, Carroli G, Lumbiganon P, Qureshi Z, et al. Moving beyond essential interventions for reduction of maternal mortality (the WHO multicountry survey on maternal and newborn health): A cross-sectional study. Lancet. 2013;381(9879):1747-55. doi: 10.1016/S0140-6736(13)60686-8. [PubMed: 23683641]. 
15. Ghazivakili Z, Lotfi R, Kabir K, Norouzi Nia R, Rajabi Naeeni M. Maternal near miss approach to evaluate quality of care in Alborz province, Iran. Midwifery. 2016;41:118-24. doi: 10.1016/j.midw.2016.08.009. [PubMed: 27614273].

16. Xin H. Editorial: Health disparities-an important public health policy concern. Front Public Health. 2017;5:99. doi: 10.3389/fpubh.2017.00099. [PubMed: 28516084]. [PubMed Central: PMC5413494].

17. Sepehrdoust $H$. Health care analysis and regional disparities in different provinces of Iran. Iran Econ Rev. 2009;14(24):113-34.

18. Biranvandzadeh M, Sorkhkamal K. Assessment of development level of Sistan and Baluchistan province compared to other Iran's provinces. Int J Architect Urban Dev. 2015;5(1):69-76.

19. Barooti E, Rezazadehkermani M, Sadeghirad B, Motaghipisheh S, Tayeri S, Arabi M, et al. Prevalence of iron deficiency anemia among Iranian pregnant women; A systematic review and meta-analysis. J Reprod Infertil. 2010;11(1):17-24. [PubMed: 23926476]. [PubMed Central: PMC3719272].

20. Ivoke N, Eyo EE, Ivoke ON, Nwani CD, Odu EC, Asogha CN. Anemia prevalence and associated factors among women attending antenatal clinic in South Western Ebonyi State, Nigeria. Int J Med Med Sci. 2013;46(1):1354-9.

21. Jabir M, Abdul-Salam I, Suheil DM, Al-Hilli W, Abul-Hassan S, Al-Zuheiri A, et al. Maternal near miss and quality of maternal health care in Baghdad, Iraq. BMC Pregnancy Childbirth. 2013;13(1):11. doi: 10.1186/14712393-13-11.

22. Oliveira FC Jr, Surita FG, Pinto E Silva JL, Cecatti JG, Parpinelli MA, Haddad SM, et al. Severe maternal morbidity and maternal near miss in the extremes of reproductive age: Results from a national crosssectional multicenter study. BMC Pregnancy Childbirth. 2014;14:77. doi: 10.1186/1471-2393-14-77. [PubMed: 24555831]. [PubMed Central: PMC3975952].

23. Haddad SM, Cecatti JG, Souza JP, Sousa MH, Parpinelli MA, Costa ML, et al. Applying the maternal near miss approach for the evaluation of quality of obstetric care: A worked example from a multicenter surveillance study. BioMed Res Int. 2014;2014. doi: 10.1155/2014/989815. [PubMed: 25147830]. [PubMed Central: PMC4132359].

24. Chong $\mathrm{N}$. The lancet' on achieving maternal health goals in the sdg era: Tackling diversity and divergence. New Security Beat; 2016, [cited 14 Aug 2018]. Available from: https://www.newsecuritybeat.org/2016/ $11 /$ the-lancet-achieving-maternal-health-goals-sdg-era-tacklingdiversity-divergence/.

25. Kasahun AW, Wako WG. Predictors of maternal near miss among women admitted in Gurage zone hospitals, South Ethiopia, 2017: A case control study. BMC Pregnancy Childbirth. 2018;18(1):260. doi: 10.1186/s12884-018-1903-1. [PubMed: 29940889]. [PubMed Central: PMC6019215].

26. Wahlberg A, Roost M, Haglund B, Hogberg U, Essen B. Increased risk of severe maternal morbidity (near-miss) among immigrant women in Sweden: A population register-based study. BJOG. 2013;120(13):1605-11. discussion 1612. doi: 10.1111/1471-0528.12326. [PubMed: 23786308].

27. Daru J, Zamora J, Fernandez-Felix BM, Vogel J, Oladapo OT, Morisaki $\mathrm{N}$, et al. Risk of maternal mortality in women with severe anaemia during pregnancy and post partum: A multilevel analysis. Lancet Glob Health. 2018;6(5):e548-54. doi: 10.1016/S2214-109X(18)30078-0. [PubMed: 29571592].

28. Miller S, Abalos E, Chamillard M, Ciapponi A, Colaci D, Comande D, et al. Beyond too little, too late and too much, too soon: A pathway towards evidence-based, respectful maternity care worldwide. Lancet. 2016;388(10056):2176-92. doi: 10.1016/S0140-6736(16)31472-6. [PubMed: 27642019].

29. Liyew EF, Yalew AW, Afework MF, Essen B. Incidence and causes of maternal near-miss in selected hospitals of Addis Ababa, Ethiopia. PLoS One. 2017;12(6). e0179013. doi: 10.1371/journal.pone.0179013. [PubMed: 28586355]. [PubMed Central: PMC5460898].

30. Abdel-Raheem SS, Mahran DG, Al-Attar GST, Qayed MH, Zareh ZEA, Othman EEDRA. Magnitude and pattern of maternal near-miss cases admitted to Women's Health Hospital, Assiut University.JCurrMed Res Pract. 2016;1(3):92. doi: 10.4103/2357-0121.199360.

31. Ntoimo LF, Okonofua FE, Ogu RN, Galadanci HS, Gana M, Okike ON, et al. Prevalence and risk factors for maternal mortality in referral hospitals in Nigeria: A multicenter study. Int JWomens Health. 2018;10:6976. doi: 10.2147/IJWH.S151784. [PubMed: 29440934]. [PubMed Central: PMC5798564].

32. Woldeyes WS, Asefa D, Muleta G. Incidence and determinants of severe maternal outcome in Jimma University teaching hospital, southWest Ethiopia: A prospective cross-sectional study. BMC Pregnancy Childbirth. 2018;18(1):255. doi: 10.1186/s12884-018-1879-x. [PubMed: 29925329]. [PubMed Central: PMC6011243].

33. Thaddeus S, Maine D. Too far to walk: Maternal mortality in context. Soc Sci Med.1994;38(8):1091-110. doi:10.1016/0277-9536(94)902267. [PubMed: 8042057].

34. Assarag B, Dujardin B, Delamou A, Meski FZ, De Brouwere V. Determinants of maternal near-miss in Morocco: Too late, too far, too sloppy? PLoS One. 2015;10(1). e0116675. doi: 10.1371/journal.pone.0116675. [PubMed: 25612095]. [PubMed Central: PMC4303272].

35. Lewis $\mathrm{G}$. The cultural environment behind successful maternal death and morbidity reviews. BJOG. 2014;121 Suppl 4:24-31. doi: 10.1111/14710528.12801. [PubMed: 25236630]. 